\title{
TEACHING TEACHERS: COULD I DESIGN AND BUILD A TINY SMART ROBOT?
}

\author{
Witold Kinsner, M.G.(Ron) Britton*, and Jeff Cieszecki** \\ Cognitive Systems Laboratory \\ Department of Electrical and Computer Engineering \\ * Faculty of Engineering \\ University of Manitoba \\ Winnipeg, MB, Canada R3T 5V6 \\ and ** Seven Oaks School Division, 711 Jefferson Ave., Winnipeg, MB R2V 0P7 \\ w.kinsner@ieee.org
}

\begin{abstract}
This paper describes a sample project that involves the construction and testing of a small robot. The project has been developed in the form of a workshop for both students and the teachers. The objectives of the workshop were to (i) attract new students to the electrical and computer engineering programs by exciting their imagination and fostering their innate curiosity, (ii) provide students with the background to build and test mechatronics devices, (iii) give students practical experience with sensors, electronics, soldering, mechanical construction, and test equipment, (iv) teach students how to work in small groups, and (v) disseminate the experience to other students, as well as their teachers and parents. This workshop has been delivered directly to high-school students at both the Science and Engineering Symposium for the Peguis First Nation in Manitoba, and to grade 9 to 11 students at the Space Adventure Camp at the University of Manitoba. The events were developed to encourage senior highschool students to consider science, engineering and technology at the university and college levels.
\end{abstract}

Keywords: Outreach programs, teaching pre-university students, teaching teachers, mechatronics, small robots.

\section{INTRODUCTION}

Attracting students to engineering is an increasingly challenging problem. One of the major reasons is the perception of students and their parents that there are no jobs in engineering because they have been outsourced to other countries. In response to this challenge, many universities have increased outreach activities to highschools, technical colleges, and even primary schools. The activities range from standard presentations about university capabilities, to hands-on workshops, special events, and dedicated interactions (mentorship) with selected students. However, although necessary, such traditional outreach presentations to students in primary schools, high schools, vocational schools, and technical colleges have produced limited results. Various extended university-related exciting summer camps and summer schools produce better outcomes than short presentation. Although university mentorship to students in high schools addresses a small number of students, it has a very high rate of success in terms of those students registering in engineering.

Among those activities, teaching teachers (or training the trainers) through workshops and direct hands-on project development is considered most effective because of the multiplying factor (one teacher sees many students during a day or a week). As explained in Sec. 2, since the multiplying factor is extremely high, the Institute of Electrical and Electronics Engineers (IEEE, with over 400,000 members) has started a special program to assist teachers in teaching engineering and science in high schools. The program, called Teachers In-Service Program (TISP), provides many resources available to teachers, some of which are similar to the workshop described in this paper. Our unique project involves the construction, testing and evaluation of a small robot, and has been designed as a workshop for either students or teachers.

Before describing the actual workshop, the next section addresses the broader question of how we attract students to engineering and sciences.

\section{STUDENT ATTRACTORS}

Finding the best ways of instilling the excitement and love of learning requires understanding not only of the natural forces and standard activities that bring students to the university, but also of special augmented activities and multi-hub activities [Kins11].

The natural driving forces capable of bringing students to engineering, technology and sciences include exceptional talent, curiosity, availability of job, parental and cultural preferences, and the experience of school counselors, as shown in Fig. 1. 


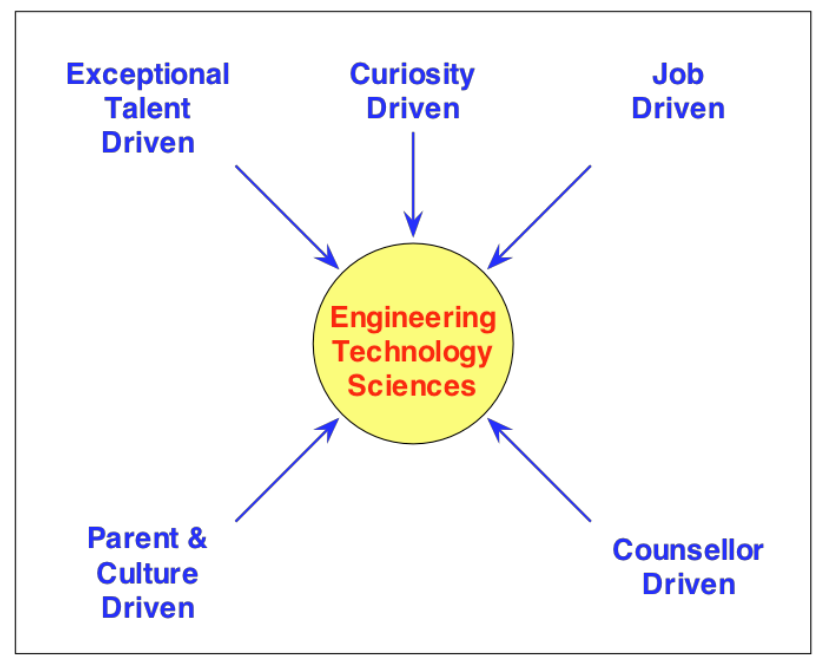

Fig. 1. Natural forces behind decisions.

Traditional outreach activites include presentations, tours, students competitions, and special events such the Engineering Week, as shown in Fig. 2. Oral presentations to senior high-school and college students are often done at the students' locations, but they can also be done at the universities. Tours to university and college labs, to industrial laboratories and facilities, and to research and development (R\&D) institutions are intended to demonstrate their facilities to the students directly. Various student competitions such as science fairs, robot competitions, hovercraft and speed-car races have been attractive and produced hands-on experience to the students. Of increasing importance are programming competitions. The annual Engineering Week has been organized by Engineers Canada in each province for many years now. It involves numerous exhibits of university capabilities, competitions and demonstrations at easily-accessible shopping malls.

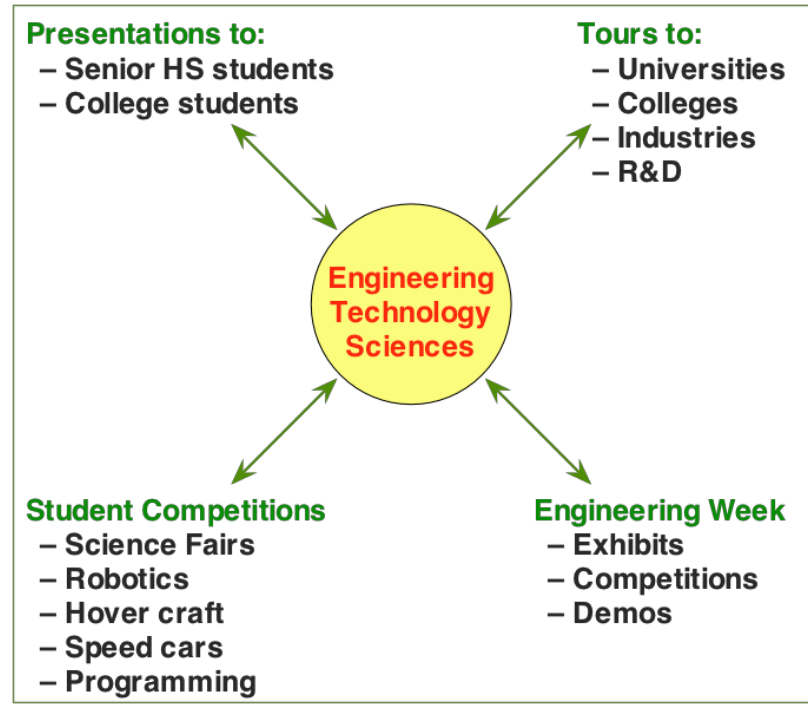

Fig. 2. Traditional outreach activities.
In addition to the traditional outreach activities, various locations in Canada and elsewhere have been developing augmented outreach activities, including adventure camps, special courses, undergraduate and graduate competitions, and teaching teachers workshops, as shown in Fig. 3.

The adventure camps include camps on aerospace, smart systems, Shad Valley, and MiniUniversity for primary students. The first three examples are designated for senior high-school students with sufficient knowledge to appreciate the activities involved. The Manitoba Space Adventure Camp was offered a few times already, and its experience is described in another paper [KiBC11]. Such camps require much preparation and resources to make them interesting.

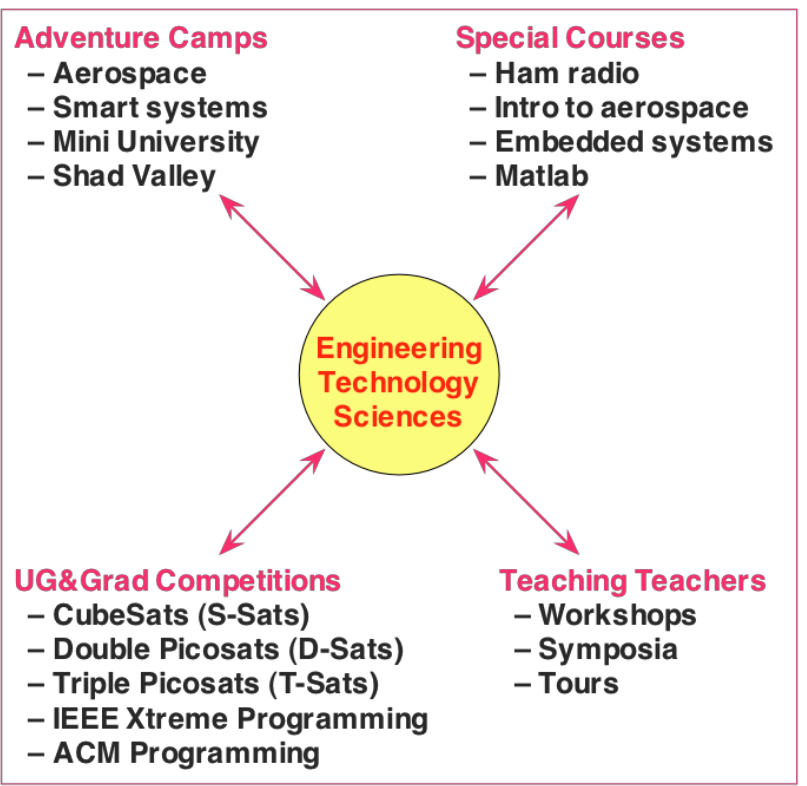

Fig. 3. Augmented outreach activities.

Special courses have also been developed to attract students. Examples include courses on amateur (ham) radio theory and practice, and on introduction to aerospace, as well as workshops on embedded systems and Matlab. Different versions of the ham radio course have been offered at the University of Manitoba (UofM), Red River College, and several high schools in Manitoba. The UofM course was attended by graduate and undergraduate students, as well as students from a high school.

Another important group of activities in this category includes competitions for graduate, undergraduate and possibly high-school students. Since the most difficult competitions involve both hardware and software (systems), they can best benefit university students, with high-school students being observers mostly. Examples include the design, implementation and testing of a 
CubeSat (a single picosatellite, S-Sat, whose size is $10 \times$ $10 \times 10 \mathrm{~cm}$ ), as well as a double picosatellite (D-Sat) for the QB50 constellation, and a triple satellite (T-Sat) for the Canadian Satellite Design Challenge. The T-Sat is described in another paper [KBSD11].

Programming competitions are easier to organize and deliver. For example, the 24-hour Association of Computing Machinery (ACM) programming competition and the IEEE Xtreme Programming contest (with 5,000 students participating last year) have been offered on a yearly basis. They too could involve high-school students. The multiplying factor of this group is quite high.

The fourth group in this category is teaching teachers that include workshops, symposia and tours to R\&D labs. This paper describes a specific workshop that falls into this group of activities. Since the multiplying factor of this group is extremely high, IEEE has started a special program to assist teachers in teaching engineering and science in high schools. The program is called Teachers In-Service Program (TISP). The mission of TISP is to foster interest in engineering, science and mathematics among students from grades 7 through 12 by providing teachers with tools and training that can be used to give students interesting experience and fun with engineering and science topics in the classroom. TISP provides a forum for IEEE volunteers to demonstrate the application of engineering, science and mathematics concepts by sharing their real-world experiences with local pre-university educators. IEEE also offers training workshops for its volunteers on how to provide in-service programs to local pre-university educators. There were two such Canadian TISP workshops, one in 2009, and one in 2011. Under the guidance of TISP, many courses have been developed for teachers and students, including TryEngineering [TryE11], TryScience [TryS11], TryNano [TryN11], and E-Scientia [eSci11]. They also plan to introduce TryComputing soon. Since 2001, over 130 in-service presentations have been developed and presented by IEEE volunteers. Approximately 3,200 preuniversity educators have participated in an in-service program, impacting almost 350,000 students worldwide. All 20 IEEE Canada Sections are active in TISP.

Outreach activities can also benefit from collaboration with other organizations that have similar objectives, as shown in Fig. 4. This collaborative outreach is termed multi-hub outreach activities. For example, any university has an IEEE student branch that is dedicated to expanding the educational and hands-on experience of undergraduate students. The branch has development and test equipment that can be used in the workshops. The student branch gives many workshops that can augment the workshops provided by the university. The same applies to other organizations such as the UofM Women in Science and Engineering (WISE) who delivered over 1,000 presentations to high schools in
2010, UofM Engineering Society (UMES), UofM Space Applications and Technology Society (UMSATS), and UofM Amateur Radio Society (UMARS).

Another important activity in this category is university mentorship to high-school students. Let us assume that a high school has a mentorship program with a university. Then, a teacher responsible for the program selects a talented student. The student selects a topic of interest and its potential. Example of topics suggested to the students who attended the Space Adventure Camp include cognitive systems, computational intelligence, robotics, autonomous agents, biomedical engineering, embedded computing, autonomous vehicles, sensor networks, computer networks, telecommunication devices and systems including smart antennas, power devices and systems, biomedical engineering, electrical engineering, computer engineering, mechatronics, mechanical engineering, manufacturing engineering, civil engineering, materials engineering, near-space engineering, aerospace engineering, and space science. The student's interest is then matched with a professor in the area. The student spends one day a week at the university, working on the project with the professor and graduate students. At the end of a successful project, the student presents the project results to their school. The success of this program is very high in terms of the number of students who select Faculty of Engineering. While at the university, the students often become active in various student bodies.

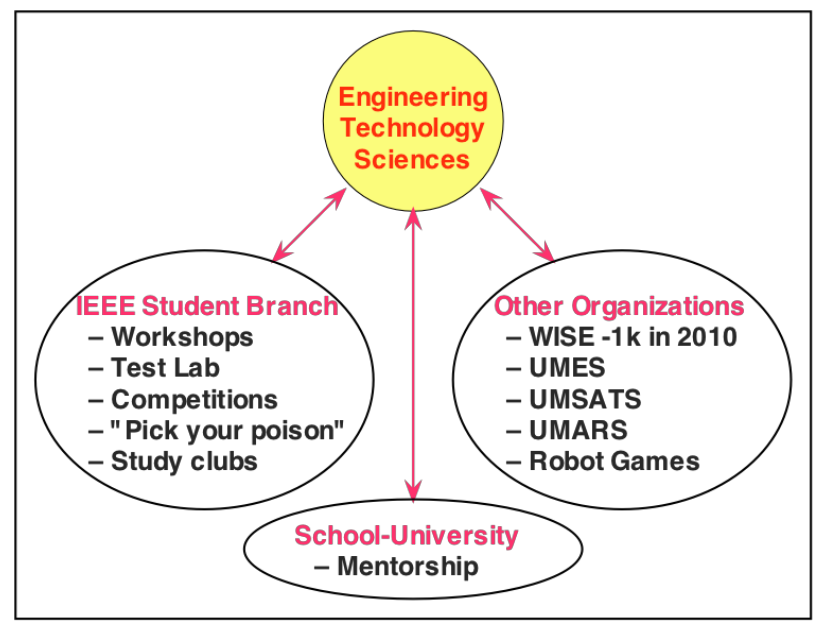

Fig. 4. Multi-hub outreach activities.

This overview of outreach activities indicates that teaching teachers is only one part of the multi-facet array of approaches to instillig or rekindling the excitement and love of learning in students. 


\section{THE TINY-ROBOT WORKSHOP}

\subsection{Workshop Overview}

The hands-on project has been developed as a workshop for both students and teachers. The symposium was developed to encourage senior high-school students to consider science, engineering and technology at the university and college levels. The objectives of the workshop were to (i) attract new students to the electrical and computer engineering programs by exciting their imagination and fostering their innate curiosity, (ii) provide students with the background to build and test mechatronics devices [Bolt03], (iii) give students practical experience with sensors, electronics, soldering, mechanical construction, and testing equipment [Brag02], (iv) teach students how to work in small groups, (v) disseminate the experience to other students, as well as their teachers and parents. Objectives for the teachingteachers workshops are extended to include alternative designs.

The workshop consists of three parts: (i) oral, (ii) hands-on development, and (iii) analysis. The oral presentation introduces the concept of a robot, and particularly the BEAM (Biology, Electronics, Aesthetics, and Mechanics) robot by discussing its components and their interactions and constraints. It then attempts to design a small robot that could be implement with inexpensive components. The objective of this part is to show that mathematics, physics, electronics, circuits, and design principles are all needed to accomplish such a task. The hands-on part of the workshop demonstrates how a paper-design is translated into a practical implementation. The key objective of the entire workshop is to give the assembled and tested robot to each student so that they could experiment with their machines at school, and to show them to their parents and friends. This provides an important multiplying factor.

Since the assembly of each robot is time consuming, about 2 hours should be assigned for a session. The number of students should be two per group. A workshop can handle 24 students per session.

This section describes various stages of the preparation to this extensive workshop, including the equipment used and its acquisition, the preparation of some of the project parts and test equipment, development of a supervisory team of undergraduate students that provided a one-to-one interaction with each workshop participant, as well as testing, and safety procedures employed to protect the participants

\subsection{Requirements and Constraints}

The robot must contain few parts so that each student could complete the assembly in two hours. The robot should not contain a limited-capacity battery, but run from a solar cell to expose the students to alternative energy sources. The robot should not be driven by a programmed computer because the students have not been exposed to microcontrollers and microprocessors and low-level programming before. The robot should involve the smallest number of motors so that the power required to drive it and the weight be both minimal. The electronic circuit capable of driving the robot should involve the fewest number of resistors and capacitors so that the number of soldered joints be minimal. The circuit should be placed on a printed circuit board (PCB) for integrity and compactness. The circuit should also be understandable so that the students could explain it to their to parents, teachers and friends. The robot should be testable by an inexperienced student. It should also be rugged so that it continues working through many successive demonstrations to a variety of audiences.

\subsection{Robot Schematic and Parts}

A robot that satisfies the above requirements has been developed by Solarbotics in Calgary in the form of the Solarspeeder Solaroller 2 (\$26/unit) [Sola10a]. The schematic and its layout on a PCB are shown in Fig. 5a and $b$, respectively.

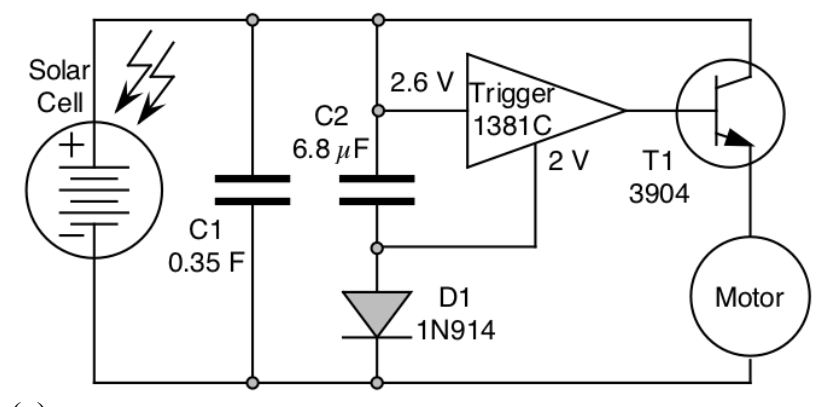

(a)

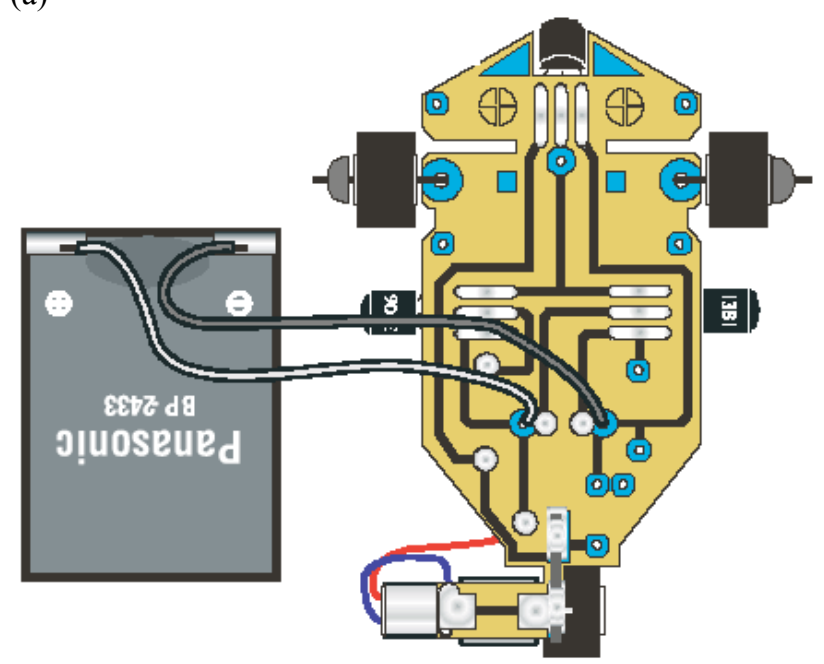

(b)

Fig. 5. Solarbotics' SolaRoller 2 (SR2).

(a) Schematic of SR2, (b) Component layout of SR1.

It has one high-efficiency DC motor converted from a vibrator found in cell phones by removing its offset 
weight from the shaft. It has three wheels, one driven by the motor and two providing stability to the roller. It is powered from a small solar cell $(24 \times 33 \mathrm{~mm})$. It has one very large storage capacitors $(0.35 \mathrm{~F})$ and one timing capacitor $(6.8 \mu \mathrm{F})$, one high-conductance switching diode (1N914), one common NPN silicon switching transistor (2N3904) and one hard-to-get voltage trigger integrated circuit (1381C), and no resistors. The letter C in 1381 indicates the trigger voltage of $2 \mathrm{~V}$.

When the voltage on $\mathrm{C} 2$ reaches about $2.6 \mathrm{~V}$, the trigger 1381 turns on, and provides enough current to turn on the switching transistor 3904. This closes the path from the storage capacitor $\mathrm{C} 1$ to the motor, and the motor starts running. Since diode D1 protects C2 from rapid discharging, the voltage on $\mathrm{C} 2$ drops slowly, thus keeping the motor running as long as the current overcomes the friction of the motor.

\subsection{Reusable Parts}

The workshop also requires reusable parts such as soldering tools (soldering iron and cleaning sponge), solder, part handling tools (small pliers and wire strippers), testing tools (multimeters), Extension cords to each the work benches, and safety tools (good-quality glasses and a first-aid kit). More specifically, a minimum set is listed next:

- 12 Soldering irons and stations from Active Electronics (\$30/unit)

- 1 Solder Sn63Pb37 (\$17/spool)

- $\quad 12$ Needle nose mini pliers (\$3/unit)

- 12 Wire strippers (\$2/unit)

- 12 Multimeters (\$25/unit)

- $\quad 129 \mathrm{~V}$ Batteries (\$17/pack)

- 6 Extension cords (\$9/unit)

- 24 Safety glasses (\$11/unit)

- 2 First aid kit (\$30/unit)

\subsection{Functional Description (Schematic \& Physical)}

At the beginning of the workshop, the concept of the BEAM robot is illustrated and explained. The operation of the Solaroller 2 is also illustrated by splitting its schematics into functional stages (off, on, off). Since the students are not familiar with schematic symbols of physical components and their interconnections in the form of a schematic circuit, now is the opportunity to explain that relationship between their abstract and physical representations.

Since the students are not familiar with the components themselves (e.g., the resistor R, capacitor $\mathrm{C}$, inductor $\mathrm{L}$, diode $\mathrm{D}$, transistor $\mathrm{T}$, integraded circuits $\mathrm{IC}$, and others), it is also necessary to explain their roles and properties. Electrical entities (i.e., voltage V, current I, voltage drop, Ohm's law V = RI, energy E, and power P) should also be explained.
In addition, it is important to explain measuring procedures using a multimeter. The distinction between a calculated value of a component and the standard value must also be explained. Since a volume manufacturing of a device cannot match the standard value exactly, the concept of device tolerance (1 to $20 \%$ ) should also be explained. The concept of tolerance can be reinforced during the training session by measuring several resistors and finding out if they fit in the expected tolerance.

\subsection{Soldering Training}

Since soldering skills are often acquired for a life time, this part of the workshop should concentrate on the role of soldering, solder types and their properties, types and the role of fluxes, good against bad joints, and how to inspect for the quality of joints. For example, the eutectic $\mathrm{Sn} 63 \mathrm{~Pb} 37$ solder (i.e., melting at a point of $181^{\circ} \mathrm{C}$ or $361^{\circ} \mathrm{F}$ ) should be compared against $\mathrm{Sn} 60 \mathrm{~Pb} 40$, as well as $\mathrm{Sn50Pb50}$ and high-temperature lead-free silver solders. This should be done by soldering small wires on small parts of PCBs, cut specifically for the workshop. The students should also learn about different types and wire gauges, and how to strip their insulation. A training session is illustrated in Fig. 6.

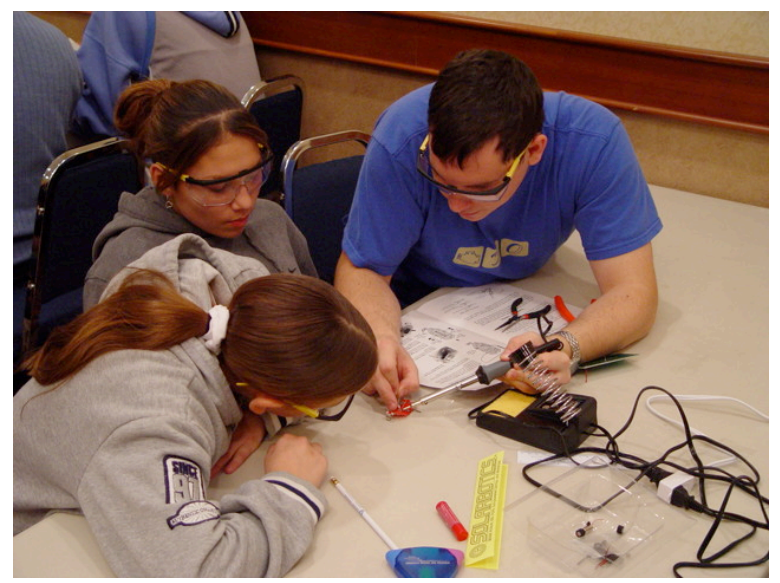

(a)

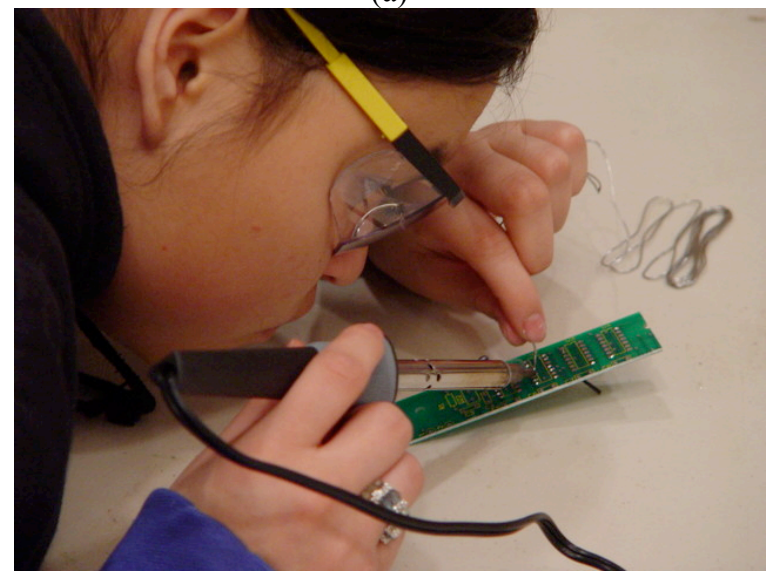

Fig. 6. (a) Explaining components. (b) Soldering training. 


\subsection{Robot Assembly}

By now, each TA should be familiar with the capabilities of their students, in order to help them assemble the robot parts according to the assembly manual [Sola10b]. At each step of the assembly, the TAs should discuss the placement of each component on the robot $\mathrm{PCB}$, and the procedure to connect it properly before soldering. One should not follow the placement and procedure described and illustrated in the assembly manual blindly. Soldering of each individual component should be verified for continuity with the ohm-meter. Soldering of large parts (e.g., the motor holder) is more difficult because it requires more heat that can damage the PCB. Soldering of the solar cell is particularly sensitive to heat.

When completed (see Fig. 7), the entire assembly should be inspected visually for any lose parts and joints.

A slide presentation is also helpful, with each step in the assembly manual projected on the screen for all to see. Although some groups of students progress fast, the slides could be used to provide the slowest time reference.

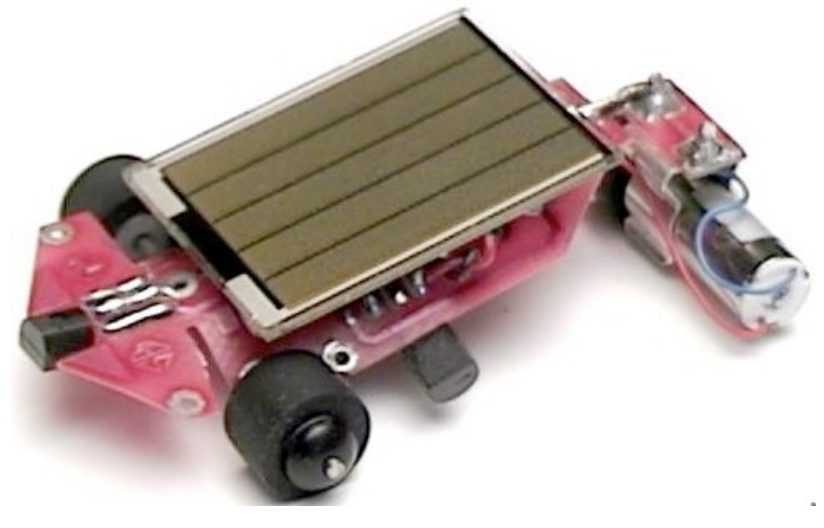

Fig. 7. Finished SolaRoller 1.

\subsection{Testing}

Once assembled, the overall functionality of the robot should be tested by charging the strorage capacitor $\mathrm{C} 1$, and by observing if the wheel turns. Since the first charging of the large storage capacitor from a small solar cell takes a long time, a high-intensity source of light is required. We have used an overhead projector, with an added advantage of projecting the robot's contour on the screen, and observing when the wheels start turning (see Fig. 8). Another light source used was a 500,000 candle power cordless spotlight, as available from different hardware stores. This is particularly useful for demonstration of the robot in schools or at exhibits.

This is also an opportunity to reinforce the concept of a steady charge against a varying charge by measuring the voltage on the storage capacitor on $\mathrm{Cl}$. since the charging is relatively slow, it is possible to measure it and record the values. A plot of the increasing voltage can then be produced. Since the measured voltage on $\mathrm{C} 1$ varies with time, one could discuss its nonlinear (exponential) behaviour. The mathematical natural Euler constant $e=2.72828 \ldots$ could also be discussed in the context of the charging of $\mathrm{C} 1$. The concept of charge, $\mathrm{Q}$, could also be discussed. Given the capacitance $\mathrm{C}$ of $\mathrm{C} 1$, and the voltage $v\left(t_{j}\right)$ measured at a given time $t_{j}$, the charge could be computed from $\mathrm{Q}=\mathrm{Cv}\left(\mathrm{t}_{\mathrm{j}}\right)$. This approach helps the students make the invisible, visible.

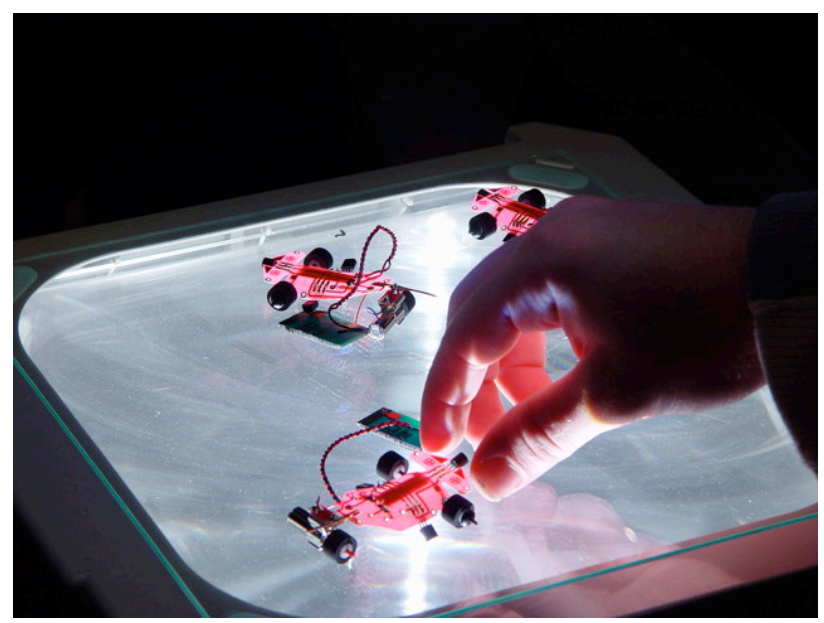

Fig. 8. Testing robots on an overhead projector.

\subsection{Review of the Project}

In reviewing the construction and testing, one could ask the students to define a capacitor, resistor, diode, transistor, diode, integrated circuit, motor, $\mathrm{PCB}$, torque, power, energy. Many other points to ponder could be introduced. For example, what makes the motor move? How does the circuit work? Why does the rotation of the motor stop? How long will it take to discharge $\mathrm{C} 1$ when the motor rotates? Is the charge on $\mathrm{C} 1$ dangerous? When does electricity become dangerous for people and other living organisms?

\subsection{What If Analysis}

The students should be encouraged to evaluate different scenarios under changes to the circuit. For example, what will happen when the large capacitor $\mathrm{C} 1$ is increased in value? What will happen when the solar cell has a larger area? The movement of the robot is nonuniform. Why is it so, and how could we change it to a uniform motion? The concept of linear and nonlinear behaviour could also be discussed. Is nature linear?

\subsection{Training Teaching Assistants}

Since the workshop is potentially dangerous due to hot soldering, solder splashing, and $120 \mathrm{~V}$ electricity involved, training of teaching assistants (TAs) is necessary. The TAs are volunteer undergraduate students from the IEEE Student Branch and other groups such as 
the UMSATS and UMARS. Each TA must go through a training session at least one week prior to the workshop, as given by the lead instructor. The training involves discussion of (i) workshop objectives, (ii) schematic circuit and its operation, (iii) types of solder and fluxes, (iv) soldering, (iv) inspection for good and cold joints, and (v) training of safety procedures. The TAs should also learn how to prepare solder for safe handling by the students, as shown in Fig. 9.

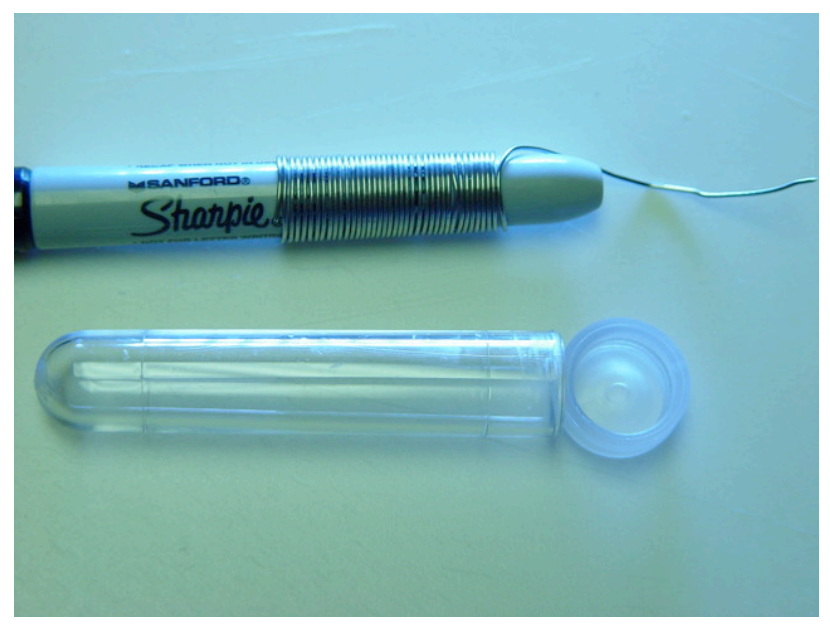

Fig. 9. Preparing solder for safe handling.

\section{CLOSING REMARKS}

This workshop has been delivered to high-school students at both the Science and Engineering Symposium for the Peguis First Nation in Manitoba, and to the Space Adventure Camp at the University of Manitoba.

The outcomes of the workshop were extraordinary in that most of the high-school students (46 out of 48) completed and tested their projects successfully. Students who were reluctant to even participate in the project at the beginning of the workshop, quickly realized that they could too complete the robots. The experience gained by our undergraduate students who supervised the workshop participants was also significant, as articulated after the workshop. We have also succeeded in communicating the key message stemming from the title of the workshop: the high-school students could not "design" the robot, as it requires knowledge taught later in our undergraduate and graduate university courses, but they could "build and test" the completed robots, thus reducing the fear of embarking on such a project. Although originally intended explicitly for the students from the Peguis First Nation, the workshop has been modified and delivered to other groups of pre-university students. Since there are quite a few ways to modify the project, the teaching teachers workshop can stress the modifications and the corresponding variations to circuit measurements and the resulting experiments.

\section{Acknowledgements}

This work was supported in part through grants from the Engineering Foundation, Faculty of Engineering, Department of Electrical and Computer Engineering, all from the University of Manitoba, Aerospace Manitoba, and MindSet, and a research grant from the Natural Sciences and Engineering Research Council (NSERC) of Canada.

\section{References}

[Bolt03] W. Bolton, Mechatronics: Electronic Control Systems in Mechanical and Electrical Engineering. Harlow, UK: Prentice-Hall, 2003 (3rd ed.), 574 pp. ISBN: 0-131-21633-3.

[Brag02] Newton C. Braga. Robotics, Mechatronics, and Artificial Intelligences: Experimental Building Blocks for Designers. Burlington, MA: Newness, 2002, 297 pp. ISBN: 0-7506-7389-3 pbk.

[eSci11] E-Scientia, 2011. Available as of April 28, 2011 from

http://www.ieee.org/education_careers/education/preuni versity/e_scientia.html

[Kins07] Witold Kinsner, "Towards cognitive machines: Multiscale measures and analysis" Intern. J. Cognitive Informatics and Natural Intelligence, vol. 1, no. 1, pp. 28-38, January-March 2007.

[Kins11] Witold Kinsner, "Creating excitement in learning and teaching," in Proc. IEEE Teachers-InService Program Workshop (Mississauga, ON; April 28-29, 2011) 2011.

[KBSD11] Witold Kinsner, M.D.(Ron) Britton, Dario Schor, Arash Fazel Darbandi, Kris Goodmanson, Cody Friesen, Emily Bashford, "Preliminary experience from the Canadian Satellite Design Challenge," in Proc. Can Engineering Education Conf. (St. John's, NL; June 6-8, 2011) 2011.

[Sola10a] SolarSpeeder SolaRoller 2. Calgary, AB: Solarbotics, 2010. Avalable as of June 2010 from http:/www.solarbotics.com/products/k_ss/resources/

[Sola10b] SolarSpeeder SolaRoller 2 Manual. Calgary, AB: Solarbotics, 2010. Avalable as of June 2010 from http://www.solarbotics.com/assets/documentation/kss_s olarspeeder2-docrevfeb102009.pdf

[TryE11] TryEngineering, 2011. Available as of April 28, 2011 from http://www.tryengineering.org/

[TryN11] TryNano, 2011. Available as of April 28, 2011 from

http://www.ieee.org/education_careers/education/preuni versity/tispt/trynano.html

[TryS11] TryScience, 2011. Available as of April 28, 2011 from http://www.tryscience.org/ 